\title{
ARTICLE OPEN \\ Trends in United States large hail environments and observations
}

\author{
Brian H. Tang (D) ${ }^{1 *}$, Vittorio A. Gensini $\mathbb{D}^{2}$ and Cameron R. Homeyer (D) ${ }^{3}$
}

Understanding trends in large hail-producing environments is an important component of estimating hail risk. Here, we use two environmental parameters, the Large Hail Parameter and the Significant Hail Parameter, to assess trends in days with environments conducive for hail $\geq 5 \mathrm{~cm}$. From 1979 to 2017 , there has been an increase in days with favorable large hail environments in central and eastern portions of the U.S. This increase has been driven primarily by an increasing frequency of days with steep midtropospheric lapse rates and necessary combinations of instability and vertical wind shear for severe thunderstorms. Annual large hail environment area is significantly, positively correlated with (1) large hail report area east of the Rocky Mountains, and (2) large hail radar-derived area in the Midwest and Northeast. This evidence suggests that there may be an environmental fingerprint on increasing large hail risk and expanding this risk eastward.

npj Climate and Atmospheric Science (2019)2:45; https://doi.org/10.1038/s41612-019-0103-7

\section{INTRODUCTION}

Hailstorms cause severe damage to crops and property, which has resulted in substantial economic losses. Over the past decade, average annual insured losses due to hail are estimated at \$8-13 billion in the U.S., and losses have increased dramatically over the last few decades (S. Bowen). Understanding the factors that are causing this increase in hail losses is of growing interest to stakeholders who wish to better understand and mitigate their hail risk. While all hail can produce damage, depending on what is being impacted, we focus on large, "significantly severe" hail $(\geq 5 \mathrm{~cm})$, because this class of hail can produce extreme amounts of damage to commonly exposed assets. ${ }^{1,2}$

A critical component of assessing hail risk is spatially estimating large hail frequency (e.g., average annual number of days with large hail at a location), and there are several approaches for estimating this frequency. First, hail observations, collected through in situ reports ${ }^{3,4}$ or instrumentation, ${ }^{5-7}$ represent the most direct way to estimate large hail frequency. Storm Data (https://www.ncdc.noaa.gov/stormevents/) contains U.S. hail reports dating back to 1955 , but using this database is challenging because of spurious trends and biases in hail reports due to nonmeteorological factors. ${ }^{8,9}$ Second, doppler radar data may be used to derive hail size proxies, ${ }^{10-12}$ but these proxies can have difficulty distinguishing between small versus large hail. ${ }^{13,14}$ Third, reanalysis and sounding datasets may be used to analyze the frequency of environmental factors that support hailstorms ${ }^{15-20}$ and, more broadly, severe thunderstorm environments. ${ }^{21-23}$ These factors are necessary, not sufficient, for large hail and do not consider convective triggers and in-cloud processes that are important for large hail formation. ${ }^{24-26}$ Given the limitations of each method for estimating frequency, we seek to employ a combination of all three approaches to assess trends in large hail frequency, because each approach supplies independent information to check for consistency.

Are changes in large hail frequency partially responsible for the observed increase in hail losses? There is large regional and decadal variability in hail incidence, regardless of size, in 20th century surface station observations across the U.S. ${ }^{27}$ While there has been no trend in empirically-modeled national hail occurrences since $1979,{ }^{15}$ and no increase in hail days since the early $1990 \mathrm{~s},{ }^{9}$ these findings do not preclude regional changes, nor do they preclude changes in other hail metrics. For example, Schlie et al. ${ }^{28}$ used a radar-based hail area metric to show that there has been an increasing number of days with hail outbreaks (90th percentile of the hail area metric) in the U.S., despite a decrease in the number of radar-based hail days from 2000 to 2011. A decrease in hail days, along with an increase in hail kinetic energy due to a shift in the distribution to larger hail sizes, has been observed in hailpad networks in Europe, ${ }^{5,6}$ possibly due to increased melting level heights and greater atmospheric instability. ${ }^{29}$ Motivated by these findings, we seek to investigate changes in regional large hail frequency using multiple approaches, and analyze possible reasons for any potential changes.

\section{RESULTS}

Trends in large hail environments and observations

The Large Hail Parameter (LHP) and the Significant Hail Parameter (SHIP; https://www.spc.noaa.gov/exper/mesoanalysis/help/help_sigh. html) are specifically designed to discriminate between environments capable of producing large hail and smaller hail. ${ }^{30}$ The LHP is a nonlinear combination of six variables: the most-unstable convective available potential energy (MUCAPE), the hail growth zone $\left(-10^{\circ} \mathrm{C}\right.$ to $\left.-30^{\circ} \mathrm{C}\right)$ thickness $\left(\mathrm{THK}_{\mathrm{HGZ}}\right)$, the $700-500-\mathrm{hPa}$ lapse rate $\left(\mathrm{LR}_{7-5}\right)$, the bulk wind difference between the surface and parcel equilibrium level (Shear ${ }_{E L}$ ), the wind direction difference between the equilibrium level and 3-6-km layer $\left(\mathrm{GRWa}_{\mathrm{EL}}\right)$, and the storm-relative wind difference between the $3-6-\mathrm{km}$ and $0-1-\mathrm{km}$ layers $(\mathrm{SRWa}$ Mid $)$. The SHIP is a nonlinear combination of MUCAPE, the water vapor mixing ratio of the most-unstable parcel, the $\mathrm{LR}_{7-5}$, the 500 -hPa temperature, the bulk wind difference between 0 and $6 \mathrm{~km}$, and the freezing level.

We use the North American Regional Reanalysis ${ }^{31}$ (NARR) from 1979 to 2017 to calculate the LHP and SHIP at each reanalysis grid point. At a given grid point, we define an LHP day to be any 24-h

${ }^{1}$ Department of Atmospheric and Environmental Sciences, University at Albany - State University of New York, Albany, NY, USA. ${ }^{2}$ Department of Geographic and Atmospheric Sciences, Northern Illinois University, DeKalb, IL, USA. ${ }^{3}$ School of Meteorology, University of Oklahoma, Norman, OK, USA. *email: btang@albany.edu 
period, beginning at 1200 UTC, that has a maximum LHP that exceeds 5.8, the 25th percentile of the LHP distribution based on proximity model soundings for hail report sizes $\geq 5 \mathrm{~cm} .{ }^{30}$ A SHIP day is defined in a similar manner, using a maximum SHIP that exceeds 1.0, which is used as a guideline by forecasters to indicate an environment favorable for large hail.

The thresholds used to define an LHP and SHIP day are based on a balance. A lower threshold results in the inclusion of environments supporting smaller $(<5 \mathrm{~cm})$ hail. A higher threshold excludes areas where large hail is uncommon, but where trends in large hail environments may still exist. The chosen thresholds in this study represent a balance to isolate environments supporting $\geq 5 \mathrm{~cm}$ hail, while including as large of an area as reasonably possible. The resulting spatial distribution of the annual mean number of LHP and SHIP days (Fig. 1) has a strong correspondence with annual large hail frequency.
Figure 1a shows that there is a positive trend of annual LHP days over much of the central and eastern portions of the U.S., while there is a negative trend of annual LHP days in the immediate lee of the Rocky Mountains. The trend in annual SHIP days (Fig. 1b) is mostly consistent with the trend in annual LHP days, albeit trends are generally smaller, and statistically significant positive trends are concentrated within the Midwest region.

Trends in LHP days are confined to specific months, depending on the region (Fig. 2). Increases in LHP days in the south-central portions of the U.S. occur in March and April. In May and June, increases in LHP days occur farther northward over the northcentral U.S. Small increases in LHP days occur in the Northeast in June and July. Decreases in LHP days in the immediate lee of the Rocky Mountains occur mainly in July and August. The pattern of monthly trends in SHIP days is very similar (Supplementary Fig. 1).

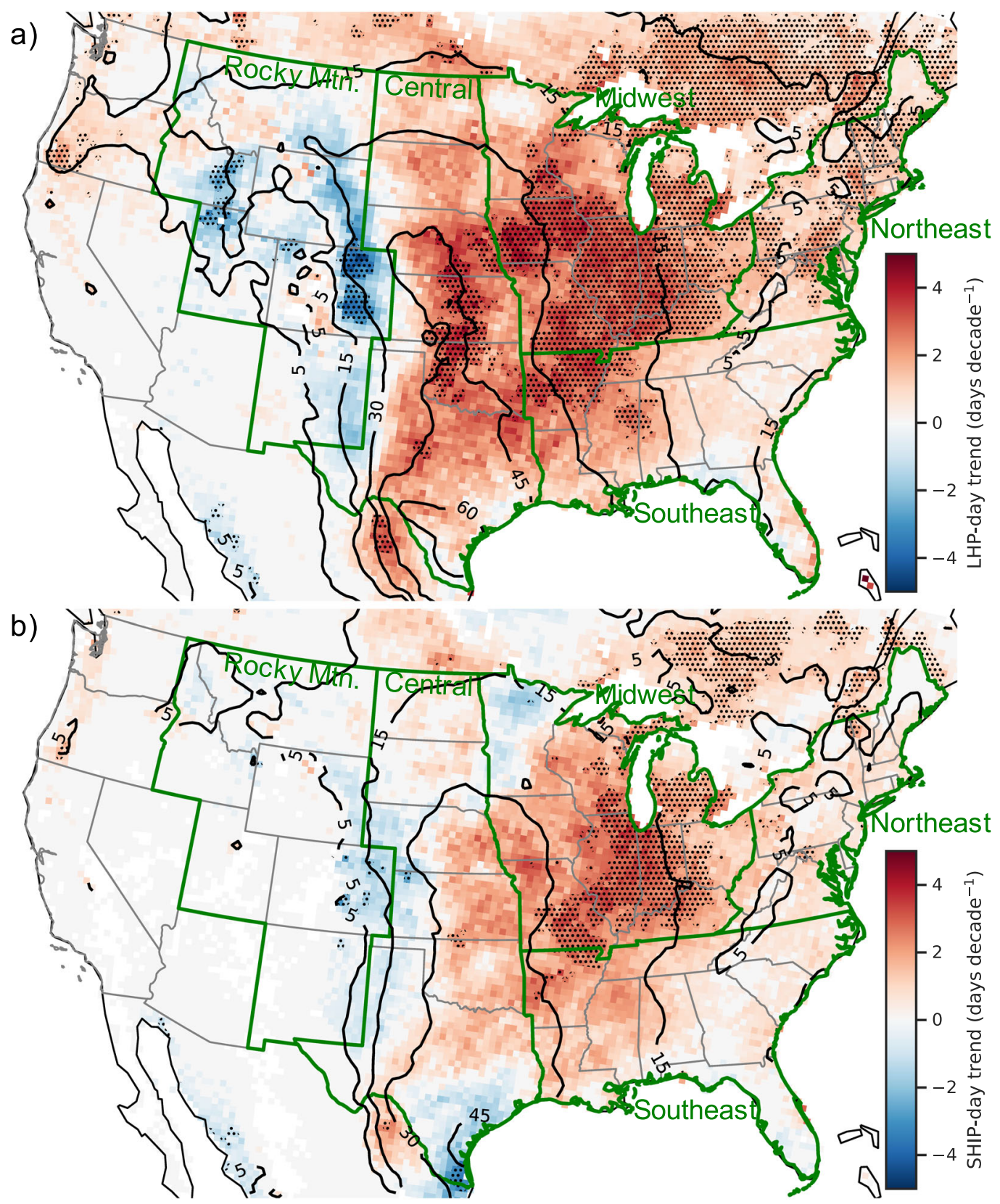

Fig. 1 Trends in annual large hail environment days. Trends in a LHP days (shaded) and annual mean number of LHP days (contoured), and b trends in SHIP days (shaded) and annual mean number of SHIP days (contoured) from 1979 to 2017. Green outlines are regions referred to in the text and Fig. 3. Stippling indicates where trends are statistically significant at the $95 \%$ confidence level. 
a) Mar

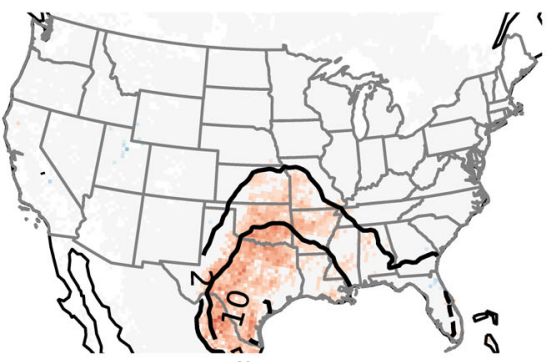

d) Jun

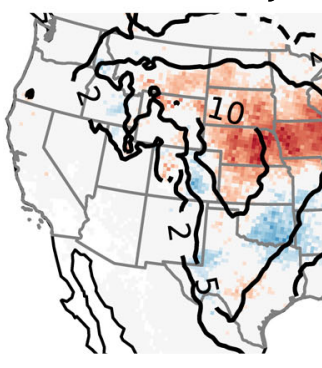

b) Apr

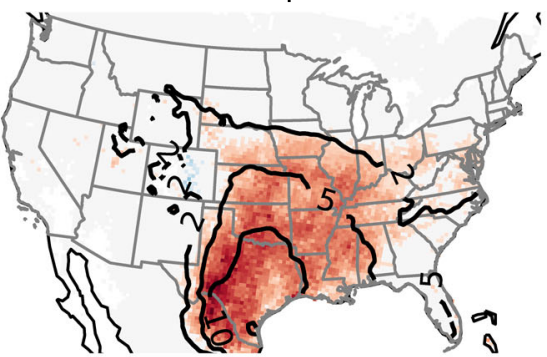

e) Jul c) May

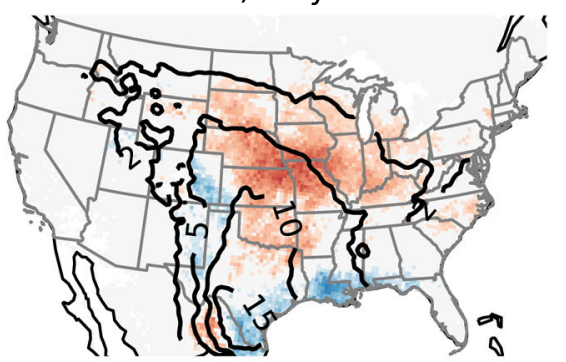

f) Aug
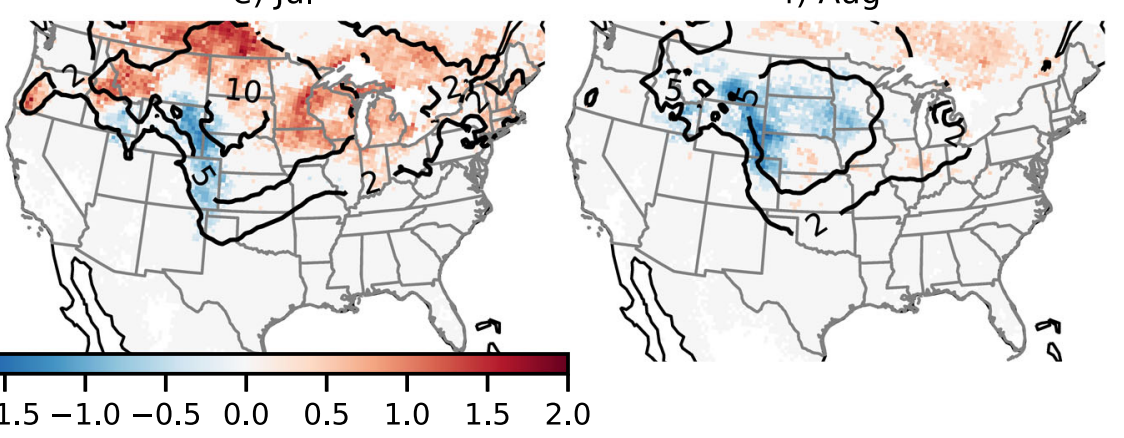

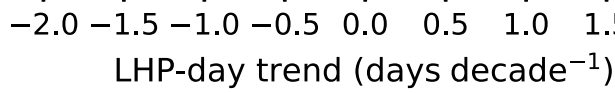

Fig. 2 Trends in monthly large hail environment days. Monthly trends in LHP days (shaded) and monthly mean number of LHP days (contoured) for a March, b April, c May, d June, e July, and f August from 1979 to 2017.

The overall pattern in LHP- and SHIP-day trends in Figs. 1 and 2 indicate there has been an expansion and eastward shift of environments conducive for large hail from 1979 to 2017. This result suggests there has been potential for an overall increase in risk of damages and losses from large hail, albeit the increase in risk would only be realized if large hail actually materializes more frequently.

To assess whether large hail has materialized more frequently, we compare annual LHP/SHIP-day area, which we will refer to as the "large hail environment area", with annual large-hail-report(LHR-)day area, which we will refer to as the "large hail report area". Here, each area refers to the areal sum of grid boxes that satisfy a LHP, SHIP, or LHR day over a given year. Due to the sparse and inhomogeneous nature of LHRs, sums over regions help to alleviate the inherent noisiness in the report data. There is a significant, positive correlation between the annual large hail environment and report area (Fig. 3) when averaged nationally and over each region, except the Rocky Mountains region. The high covariance in interannual variability suggests that there is indeed greater annual large hail report area when there is greater annual large hail environment area east of the Rocky Mountains. Moreover, the trends in both areas mimic one another, especially in regions that have a higher population density (Midwest, Northeast, and Southeast). As a result, these data suggest the possibility that increases in the frequency of large hail reports may be partially attributed to increases in the frequency of LHP/SHIP days through the analysis period. One must keep in mind that increases in LHRs are also due to non-meteorological factors (e.g., changes in reporting practices, establishment of the NextGeneration Radar network, and increases in observers), ${ }^{8,9}$ although restricting the scope to large hail sizes and examining these data through areal sums of LHR days, and not raw counts, diminishes the effect of these non-meteorological factors. ${ }^{9}$

To obviate these non-meteorological factors, the maximum estimated size of hail (MESH), ${ }^{10}$ derived from 3D-gridded radar (GridRad) $^{33}$ data from 1995 to 2016, is used to calculate the MESHday area, using a MESH threshold of $6.4 \mathrm{~cm}$ (see "Methods" section), which we will refer to as the "large hail radar-derived area". There is a significant, positive correlation between the annual large hail environment area and radar-derived area in the Midwest and Northeast regions, and there are non-significant, weak correlations in other regions (Fig. 3). There has been a general increase in the large hail radar-derived area nationally, dominated by increases in the Rocky Mountains and Central regions.

MESH data are too limited in time to definitively say whether trends in the large hail radar-derived area are consistent with the longer-term trends in large hail environment and report area. While there is a positive trend in the large hail radar-derived area nationally, it is important to keep in mind that the reliability and resolution of the radar network has increased with time. It is also important to keep in mind that having a MESH $\geq 6.4 \mathrm{~cm}$ cannot be equated to large hail actually reaching the ground, so the large hail radar-derived area is likely encompassing a wider range of hail sizes. $^{13,14}$

There is a puzzling decrease in the large hail environment area in the Rocky Mountains region, which is opposite of the increases in large hail report area in this region. There are a few possibilities for this inconsistency. The first possibility is that this region has seen large population growth (P. Mackun and S. Wilson), and it could be that these population effects are dominating the increase in large hail report area. As a result, large hail reports have become more reliable since the early $2000 \mathrm{~s} .{ }^{9}$ The correlation between LHP-day area and large hail report area increases from 0.08 to 0.51 when only considering the data after 2002. Similarly, the correlation between SHIP-day area and large hail report area increases from 0.17 to 0.43 . The second possibility is that the LHP and SHIP are not as well calibrated for high-plains and mountainous environments, where orographic effects are especially important during boreal summer. ${ }^{20}$ The third possibility is that there are biases in the NARR over the Rocky Mountains region. ${ }^{34,35}$ Evaluating these possibilities is beyond our research scope here, but it appears the statistics of large hailfall and hail environments in this region may require special consideration. 
a) National

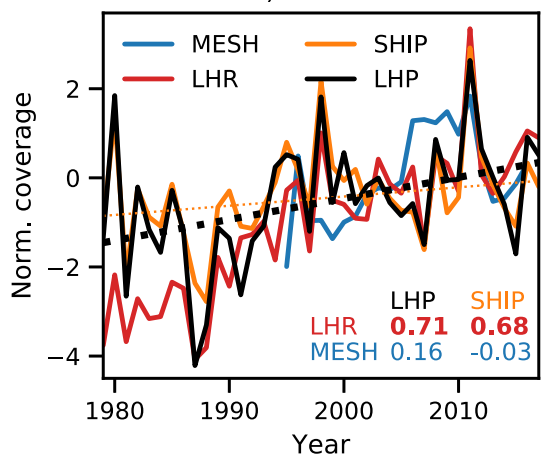

d) Rocky Mtn.

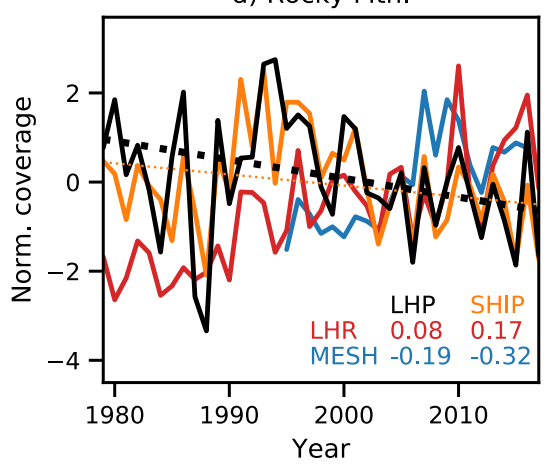

b) Midwest

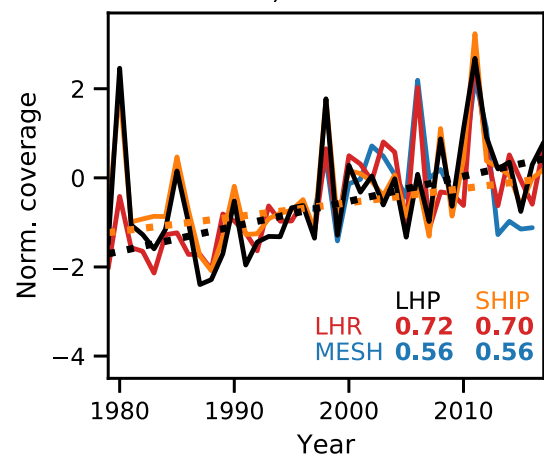

e) Central

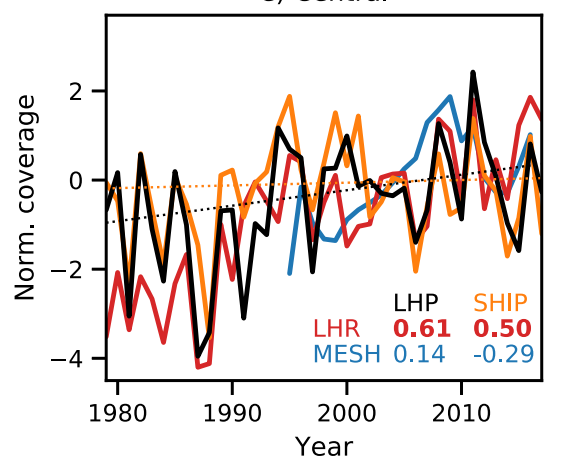

c) Northeast

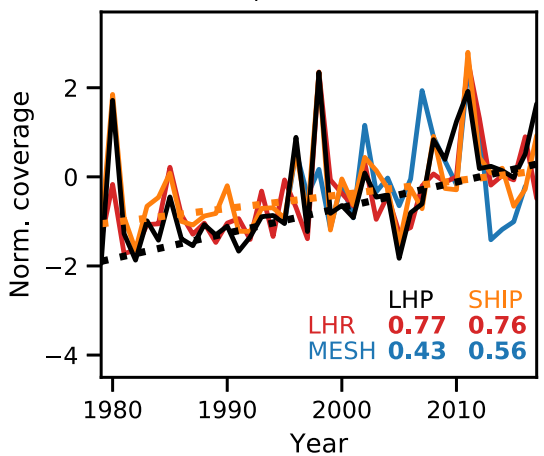

f) Southeast

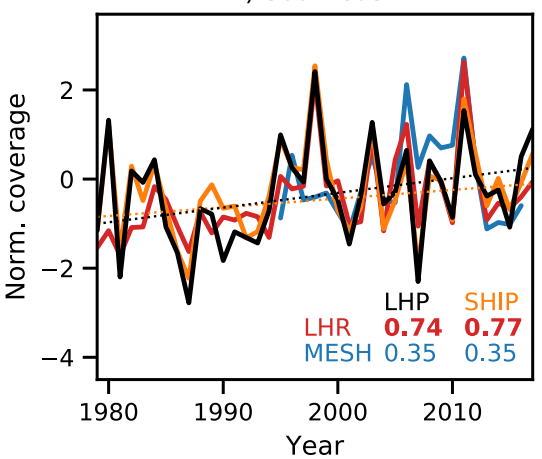

Fig. 3 Annual large hail environment, report, and radar-derived area. Normalized, annual LHP-day area (black), SHIP-day area (orange), LHRday area (red), and MESH-day area (blue) from 1979 to 2017 for a continental U.S., b Midwest, c Northeast, d Rocky Mountains, e Central, and f Southeast regions. Linear trend lines of annual LHP-day area and annual SHIP-day area are shown by dotted lines, where thick (thin) lines are (not) statistically significant. For each region, linear correlations between variables are shown in the inset. Bold text indicates statistically significant correlations at the $95 \%$ confidence level.

a) Eligible Days

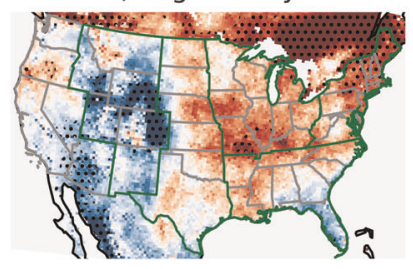

e) Shear $E L$

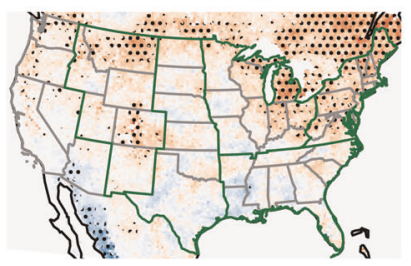

b) MUCAPE

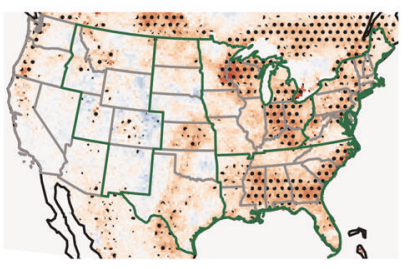

f) $G R W \alpha_{E L}$

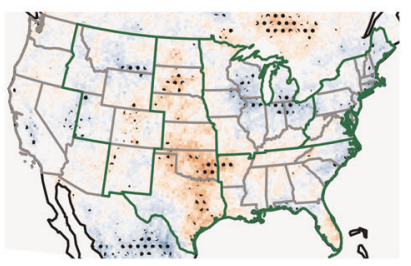

c) $T H K_{H G Z}$

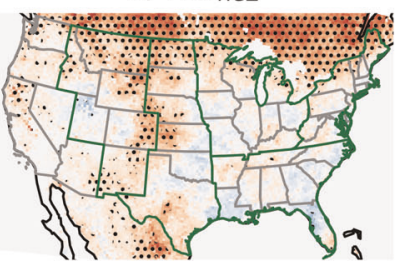

g) $S R W \alpha_{\text {Mid }}$

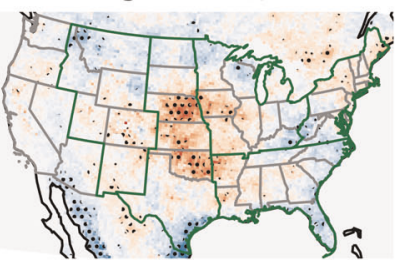

d) $L R_{7-5}$

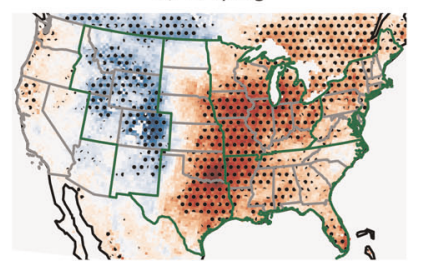

a

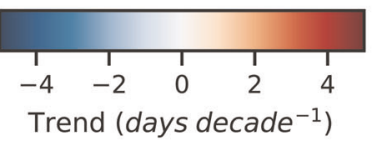

Fig. 4 Trends in LHP components. The components are a all eligible days, $\mathbf{b}$ most-unstable convective available potential energy, $\mathbf{c}$ hail growth zone thickness, $\mathbf{d}$ 700-500-hPa lapse rate, e bulk wind difference between the surface and parcel equilibrium level, $\mathbf{f}$ wind direction difference between the equilibrium level and 3-6-km layer, and $\mathbf{g}$ storm-relative wind difference between the 3-6-km and 0-1-km layers. Stippling indicates where trends are statistically significant at the $95 \%$ confidence level.

\section{Causes for LHP trends}

Figure 4 shows trends in the LHP components in order to assess which variables are causing the trends in LHP days. We subjectively choose the LHP, because it has a wider diversity of kinematic and thermodynamic components compared to the SHIP, and the results that follow are very similar if using the SHIP. First, in order for a day to potentially have a nonzero LHP, which we call an eligible day, it must simultaneously meet minimum thresholds of instability (MUCAPE $\geq 400 \mathrm{~J} \mathrm{~kg}^{-1}$ ) and bulk wind difference between the surface and $6 \mathrm{~km}\left(\right.$ Shear $_{6} \geq 14 \mathrm{~m} \mathrm{~s}^{-1}$ ). Figure $4 a$ shows there has been a decrease in eligible days in portions of the Rocky Mountains region, and there has been an increase in portions of the Midwest and Northeast. The Northeast, which is typically characterized by more marginal environments for severe weather, ${ }^{36,37}$ has seen an increase in eligible days. Although not the focus here, we also note that there has been a significant positive trend in eligible days in southern Canada, which is consistent with an observed increase in severe hail frequency over Ontario. ${ }^{38}$

When considering the six variables that encompass the LHP, we calculate trends in days that exceed variable-specific, spatially- 
varying thresholds, controlling for trends in eligible days. Instability (MUCAPE) changes have contributed to a positive trend in LHP days in portions of the Midwest, Northeast, and Southeast regions (Fig. 4b). Hail growth zone thickness changes have contributed to modest increases in LHP days in the lee of the Rocky Mountains and in the vicinity of the U.S.-Canada border (Fig. 4c). Mid-level lapse rate changes have contributed to a decrease in LHP days over the Rocky Mountains region and a broad increase in LHP days over much of the eastern half of the U. S. (Fig. 4d), which represents the most robust signal among the LHP variables. Shear (Shear ${ }_{\mathrm{EL}}$ ) changes have contributed to small increases in LHP days in parts of the Rocky Mountains, Midwest, and Northeast regions (Fig. 4e). Changes in layer wind differences associated with large hail production $\left(\mathrm{GRWa}_{\mathrm{EL}}\right.$ and $\mathrm{SRWa}$ Mid; Fig. $4 \mathrm{f}, \mathrm{g})$ have had limited contributions to trends in LHP days, with increases mainly focused in the Great Plains. The sum of the trends in Fig. $4 \mathrm{a}-\mathrm{g}$ largely resembles the spatial pattern of trends in Fig. 1a, but are not directly comparable because LHP days are defined differently and contain nonlinearities between variables. Upon using the SHIP in lieu of the LHP, similar results are found with the instability and mid-level lapse rate contributions (Supplementary Fig. 2). The remaining SHIP variables contribute less or covary strongly with the instability and mid-level lapse rate.

The combined evidence suggests the risk of large hail has increased since 1979 due in part to environmental factors. In particular, there have been positive trends in annual LHP and SHIP days east of the Rocky Mountains, together with significant, positive correlations between annual large hail environment area and large hail report area; and significant, positive correlations between annual large hail environment area and large hail radarderived area in the Midwest and Northeast. The increase in LHP days is primarily due to an increase in the number of days with steep lapse rates in mid-levels of the troposphere and, to a lesser extent, increases in the number of days with necessary combinations of instability and vertical wind shear for severe thunderstorms over the northeast U.S.

\section{DISCUSSION}

We compare our results with studies that have examined recent trends in severe weather environments and hail in the U.S. There is little indication that severe thunderstorm environments, often defined as the product of instability and vertical wind shear, have increased over the period examined (1979-2017), 22,39,40 which might appear to disagree with the positive trend in environments favorable for large hail. A fairer comparison may be with extreme thunderstorm environments, defined by Sander et al. $^{23}$ as the 99.99th percentile of the "thunderstorm severity potential", which have increased in frequency over the last few decades and have been tied to an increase in economic losses. However, caution must be exercised in these comparisons, because large hail is correlated with variables other than just instability and vertical wind shear, ${ }^{41}$ such as those variables used in the LHP and SHIP. The positive trends in large hail environment, report, and radarderived area are consistent with a positive trend in the number of hail outbreaks (greater hail area per event) over the U.S. from 2000 to $2011,{ }^{28}$ and could be consistent with the shift in the hail distribution to larger sizes observed outside the U.S., 5,29

Are the observed trends due to natural variability or part of a long-term signal associated with anthropogenic climate change? We cannot discount the possibility that the observed trends are part of natural, multidecadal variability, and 39 years of data is not enough to capture this possible variability. However, we also have reason to believe that there might be a connection with anthropogenic climate change. First, we hypothesize that the change of steep lapse rates in mid-levels of the troposphere is tied to changes in the seasonal evolution of the elevated mixed layer, which forms over source regions in Mexico and the western U.S., and is subsequently advected eastward. ${ }^{42}$ Stronger surface heating at higher elevations, tied to aridification and earlier snowmelt, ${ }^{43}$ could result in elevated mixed layers appearing earlier in the season and more frequently, increasing the probability of large hail events as severe thunderstorms form in these elevated-mixed-layer environments. ${ }^{44}$ Second, we hypothesize that there are more favorable background or synoptic-scale patterns for increased instability and vertical wind shear in the Northeast, the reasons for which warrant further investigation. The signal of increasing instability is also consistent with projections from (downscaled) climate model projections for this century. ${ }^{45-50}$ Whereas small hail might decrease with warming, the trends identified here are consistent with studies that have found that large hail, and the risk of hail damage, might increase in the future because of anthropogenic climate change. ${ }^{29,51,52}$

One must be mindful that the NARR, as will any reanalysis, have biases and errors that affect the LHP, SHIP, and the variables that comprise them. Previous studies have noted that the NARR has spurious grid-scale precipitation events ${ }^{34}$ and low-level moisture and instability errors, ${ }^{15,22,35}$ thus introducing biases and errors into the hail parameters. Nonetheless, the NARR adequately captures convective environments when compared to observed radiosonde data, ${ }^{35}$ and the NARR has smaller instability biases than other reanalyses. ${ }^{53}$ As reanalyses improve in representing the convective environment, trends in these hail parameters should be checked for consistency.

The LHP and SHIP are conditional parameters, reflecting only the possibility of large hail based on the environment in which severe thunderstorms might develop. An avenue of possible improvement would be to combine the hail parameters (or variables that make up these parameters) with other observations that reflect the existence of thunderstorms, such as radar, lightning, and satellite data. ${ }^{54}$ Doing so would decrease the high false alarm rate these purely environmental parameters have in detecting large hail, and may allow for a more refined assessment of trends in large hail and large hail environments.

\section{METHODS}

The LHP is computed, using three hourly NARR data, at each grid point from 1979 to 2017. The LHP is zero if Shear ${ }_{6}<14 \mathrm{~m} \mathrm{~s}^{-1}$ or MUCAPE $<400 \mathrm{~J}$ $\mathrm{kg}^{-1}$. Otherwise, the LHP is defined as

$$
\begin{aligned}
\mathrm{LHP}= & \left(\frac{\text { MUCAPE }-2000}{1000}+\frac{3200-\mathrm{THK}_{\mathrm{HGZ}}}{500}+\frac{\mathrm{LR}_{7-5}-6.5}{2}\right) \\
& \left(\frac{\text { Shear }_{\mathrm{EL}}-25}{5}+\frac{\mathrm{GRWa} a_{\mathrm{EL}}+5}{20}+\frac{\mathrm{SRW} a_{\mathrm{Mid}}-80}{10}\right)+5 .
\end{aligned}
$$

Details about the step-by-step calculation of the LHP and definitions of the variables, and why they are relevant for large hail, may be found in Johnson and Sugden. ${ }^{30}$ The LHP was originally calibrated using Storm Data hail reports and Rapid Update Cycle soundings. The Sounding and Hodograph Analysis and Research Program in Python ${ }^{55}$ (SHARPpy) is used to extract the necessary variables from the NARR data to calculate the LHP. At each grid point, the daily maximum LHP is computed for each 1200-1200 UTC period. An LHP day occurs if the daily maximum LHP exceeds 5.8. The daily LHP-day area is defined to be the areal sum of grid boxes that satisfy an LHP day. Thereafter, both the LHP days, for each grid point, and LHP-day area, for each region in Fig. 3, is summed over each year.

SHIP days and SHIP-day area are computed using the NARR in a similar manner. The definition and instructions for calculating the SHIP may be found at https://www.spc.noaa.gov/exper/mesoanalysis/help/help sigh. html. A SHIP day occurs if the daily maximum SHIP over a 1200-1200 UTC period exceeds 1.0 .

Linear trends in annual LHP days, SHIP days, LHP-day area, and SHIP-day area are calculated using the Theil-Sen estimator. ${ }^{56}$ The Theil-Sen estimator is preferred over least-squares linear regression, because annual LHP days and SHIP days may not be normally distributed, especially in areas where large hail is uncommon. Statistical significance (i.e., testing for a nonzero trend) is determined at the $95 \%$ confidence level using Kendall's tau test. 
Hail reports are obtained from the National Oceanographic and Atmospheric Administration (NOAA) Storm Prediction Center Warning Coordination Meteorologist page (https://www.spc.noaa.gov/wcm/). In order to match the NARR period and hail size threshold, only LHRs occurring between 1979 and 2017, and hail report sizes $\geq 5 \mathrm{~cm}$, are retained. For each NARR grid point, an LHR day occurs if an LHR occurs within $50 \mathrm{~km}$ of that grid point for each 1200-1200 UTC period, mimicking the LHP and SHIP day calculation. The 50-km neighborhoods reduces the sparse granularity of the hail reports. Annual LHR days and LHR-day area are both calculated in the same manner as those for the LHP and SHIP.

MESH data are generated from the GridRad dataset. GridRad consists of gridded 3D radar reflectivity at a horizontal resolution of $0.02^{\circ}$, a vertical resolution of $1 \mathrm{~km}$, and a time resolution of $1 \mathrm{~h}$ from 1995 to 2016. The reflectivity is converted to the Severe Hail Index (SHI), following the algorithm from Witt et al. ${ }^{10}$. The algorithm requires estimates of the height of the $0{ }^{\circ} \mathrm{C}$ and $-20{ }^{\circ} \mathrm{C}$ isotherms, which are estimated by interpolating the MERRA-2 reanalysis ${ }^{57}$ temperatures onto the GridRad grid and times. MESH is then computed from a revised empirical fit between the $\mathrm{SHI}$ and the 95th percentile of observed hail size, following Murillo and Homeyer. ${ }^{58}$ MESH days are then computed identically to LHR days, using a MESH threshold of $6.4 \mathrm{~cm}$ and a $50-\mathrm{km}$ neighborhood. The MESH threshold was determined by maximizing the critical success index of a predictor metric and verifying metric. The predictor metric is whether or not the MESH exceeds a threshold within $50 \mathrm{~km}$ of a given grid point over a day. The verifying metric is whether or not there is a large hail report within $50 \mathrm{~km}$ of a given grid point over the same day. A threshold of $6.4 \mathrm{~cm}$ yielded the maximum critical success index (Supplementary Fig. 3 ). Note that this threshold is specific to this study. Annual MESH days and MESH-day area are both calculated in the same manner as those for the LHP and SHIP.

In order to compare the annual LHP-, SHIP-, LHR-, and MESH-day areas, it is convenient to normalize the variables. Each variable is normalized by subtracting its 1995-2016 mean and then dividing by its standard deviation over the same period. The Pearson (linear) correlation is computed between the normalized variables for their respective overlapping periods.

The contribution of each individual LHP variable to the trends in annual LHP days is assessed in a two-step process. First, at each grid point, an "eligible day" is defined to be a 1200-1200 UTC day that has one 3-hourly time step with MUCAPE $\geq 400 \mathrm{~J} \mathrm{~kg}^{-1}$ and Shear $_{6} \geq 14 \mathrm{~m} \mathrm{~s}^{-1}$, which is required in order for the LHP $>0$. As with LHP days, we calculate the trend of annual eligible days using the Theil-Sen estimator. Second, for each LHP variable, we determine a subset of eligible days, which we call "component days", above a spatially-varying threshold (except below a threshold for $\mathrm{THK}_{\mathrm{HGZ}}$ ). The threshold is determined by calculating the 25th percentile of the variable for all LHP days at a grid point. This percentile is chosen to be consistent with the definition of an LHP day. The more frequently a variable exceeds its threshold (except below its threshold for $\mathrm{THK}_{\mathrm{HGZ}}$ ), the more the variable contributes to increasing the number of LHP days. At each grid point, the annual component days are divided by the annual eligible days to calculate the relative frequency of component days. The relative frequency of component days is then renormalized by multiplying by the 1979-2017 mean number of annual eligible days. The trend for each renormalized component days is computed using the Theil-Sen estimator.

This two-step process controls for trends in annual eligible days, such that one can more fairly compare the components. For example, the annual component days of an LHP variable may appear to have a positive trend if the annual number of eligible days is increasing, simply due to more days having the prerequisite MUCAPE and Shear ${ }_{6}$, not because of any trend in the climatology of said LHP variable. After transforming to the renormalized component days, a significant, nonzero trend implies that changes in the component days cannot be explained by changes in the eligible days.

\section{DATA AVAILABILITY}

NARR data is available from NOAA. Hail reports are available from the NOAA Storm Prediction Center. GridRad is available at http://gridrad.org/.

\section{CODE AVAILABILITY}

Python scripts used to analyze and visualize the data are available upon request.
Received: 11 June 2019; Accepted: 19 November 2019; Published online: 06 December 2019

\section{REFERENCES}

1. Dessens, J., Berthet, C. \& Sanchez, J. L. A point hailfall classification based on hailpad measurements: The ANELFA scale. Atmos. Res. 83, 132-139 (2007).

2. Rasuly, A. A., Cheung, K. K. W. \& McBurney, B. Hail events across the greater metropolitan severe thunderstorm warning area. Nat. Hazards Earth Syst. Sci. 15, 973-984 (2015).

3. Ortega, K. L. et al. The severe hazards analysis and verification experiment. Bull. Am. Meteor. Soc. 90, 1519-1530 (2009).

4. Blair, S. F. et al. High-resolution hail observations: Implications for NWS warning operations. Wea. Forecast. 32, 1101-1119 (2017).

5. Berthet, C., Dessens, J. \& Sanchez, J. L. Regional and yearly variations of hail frequency and intensity in France. Atmos. Res. 100, 391-400 (2011).

6. Eccel, E., Cau, P., Riemann-Campe, K. \& Biasioli, F. Quantitative hail monitoring in an alpine area: 35 -year climatology and links with atmospheric variables. Int. J. Climatol. 32, 503-517 (2012).

7. Willmot, E., Bussmann, S., Homeier, N. \& Kubicek, A. Examples of ground-based hail, rain, and wind sensor networks operating in real-time. in 2017 IEEE International Geoscience and Remote Sensing Symposium (IGARSS) 5987-5989, https:// doi.org/10.1109/IGARSS.2017.8128374 (2017).

8. Doswell, C. A., Brooks, H. E. \& Kay, M. P. Climatological estimates of daily local nontornadic severe thunderstorm probability for the United States. Wea. Forecast. 20, 577-595 (2005).

9. Allen, J. \& Tippett, M. The characteristics of United States hail reports: 1955-2014. Electron. J. Sev. Storms Meteor. 10, 1-31 (2015).

10. Witt, A. et al. An enhanced hail detection algorithm for the WSR-88D. Wea. Forecast. 13, 286-303 (1998).

11. Kumjian, M. R. \& Ryzhkov, A. V. Polarimetric signatures in supercell thunderstorms. J. Appl. Meteor. Climatol. 47, 1940-1961 (2008).

12. Cintineo, J. L., Smith, T. M., Lakshmanan, V., Brooks, H. E. \& Ortega, K. L. An objective high-resolution hail climatology of the contiguous United States. Wea. Forecast. 27, 1235-1248 (2012).

13. Blair, S. F. et al. A radar-based assessment of the detectability of giant hail. Electron. J. Sev. Storms Meteor. 6, 1-30 (2011).

14. Ortega, K. L. Evaluating multi-radar, multi-sensor products for surface hailfall diagnosis. Electron. J. Sev. Storms Meteor. 13, 1-36 (2018).

15. Allen, J. T., Tippett, M. K. \& Sobel, A. H. An empirical model relating U.S. monthly hail occurrence to large-scale meteorological environment. J. Adv. Model. Earth Syst. 7, 226-243 (2015).

16. Púčik, T., Groenemeijer, P., Rýva, D. \& Kolář, M. Proximity soundings of severe and nonsevere thunderstorms in central Europe. Mon. Wea. Rev. 143, 4805-4821 (2015).

17. Tuovinen, J.-P., Rauhala, J. \& Schultz, D. M. Significant-hail-producing storms in Finland: Convective-storm environment and mode. Wea. Forecast. 30, 1064-1076 (2015).

18. Punge, H. J., Bedka, K. M., Kunz, M. \& Reinbold, A. Hail frequency estimation across Europe based on a combination of overshooting top detections and the ERAINTERIM reanalysis. Atmos. Res. 198, 34-43 (2017).

19. Taszarek, M., Brooks, H. E. \& Czernecki, B. Sounding-derived parameters associated with convective hazards in Europe. Mon. Wea. Rev. 145, 1511-1528 (2017).

20. Prein, A. F. \& Holland, G. J. Global estimates of damaging hail hazard. Wea. Clim. Extremes 22, 10-23 (2018).

21. Brooks, H. E., Lee, J. W. \& Craven, J. P. The spatial distribution of severe thunderstorm and tornado environments from global reanalysis data. Atmos. Res. 67-68, 73-94 (2003).

22. Gensini, V. A. \& Ashley, W. S. Climatology of potentially severe convective environments from the North American Regional Reanalysis. Electron. J. Sev. Storms Meteor. 6, 1-40 (2011).

23. Sander, J., Eichner, J. F., Faust, E. \& Steuer, M. Rising variability in thunderstormrelated U.S. losses as a reflection of changes in large-scale thunderstorm forcing. Wea. Clim. Soc. 5, 317-331 (2013).

24. Nelson, S. P. The influence of storm flow structure on hail growth. J. Atmos. Sci. 40, 1965-1983 (1983).

25. Miller, L. J., Tuttle, J. D. \& Foote, G. B. Precipitation production in a large Montana hailstorm: airflow and particle growth trajectories. J. Atmos. Sci. 47, 1619-1646 (1990).

26. Dennis, E. J. \& Kumjian, M. R. The impact of vertical wind shear on hail growth in simulated supercells. J. Atmos. Sci. 74, 641-663 (2017).

27. Changnon, S. A. \& Changnon, D. Long-term fluctuations in hail incidences in the United States. J. Clim. 13, 658-664 (2000).

28. Schlie, E. E.-J., Wuebbles, D., Stevens, S., Trapp, R. \& Jewett, B. A radar-based study of severe hail outbreaks over the contiguous United States for 2000-2011. Int. J. Climatol. 39, 278-291 (2019). 
29. Dessens, J., Berthet, C. \& Sanchez, J. L. Change in hailstone size distributions with an increase in the melting level height. Atmos. Res. 158-159, 245-253 (2015).

30. Johnson, A. W. \& Sugden, K. E. Evaluation of sounding-derived thermodynamic and wind-related parameters associated with large hail events. Electron. J. Sev. Storms Meteor. 9, 1-42 (2014).

31. Mesinger, F. et al. North American regional reanalysis. Bull. Am. Meteor. Soc. 87, 343-360 (2006)

32. Allen, J. T. et al. An extreme value model for U.S. hail size. Mon. Wea. Rev. 145, 4501-4519 (2017).

33. Bowman, K. \& Homeyer, C. Gridrad - Three-dimensional gridded Nexrad WSR-88D radar data, https://doi.org/10.5065/D6NK3CR7 (2017).

34. West, G. L., Steenburgh, W. J. \& Cheng, W. Y. Y. Spurious grid-scale precipitation in the North American Regional Reanalysis. Mon. Wea. Rev. 135, 2168-2184 (2007).

35. Gensini, V. A., Mote, T. L. \& Brooks, H. E. Severe-thunderstorm reanalysis environments and collocated radiosonde observations. J. Appl. Meteor. Climatol. 53, 742-751 (2014)

36. Hurlbut, M. M. \& Cohen, A. E. Environments of northeast U.S. severe thunderstorm events from 1999 to 2009. Wea. Forecast. 29, 3-22 (2014).

37. Vaughan, M. T., Tang, B. H. \& Bosart, L. F. Climatology and analysis of high-impact, low predictive skill severe weather events in the northeast United States. Wea. Forecast. 32, 1903-1919 (2017).

38. Cao, Z. Severe hail frequency over Ontario, Canada: Recent trend and variability Geophys. Res. Lett. https://doi.org/10.1029/2008GL034888 (2008).

39. Robinson, E. D., Trapp, R. J. \& Baldwin, M. E. The geospatial and temporal distributions of severe thunderstorms from high-resolution dynamical downscaling J. Appl. Meteor. Climatol. 52, 2147-2161 (2013).

40. Tippett, M. K., Allen, J. T., Gensini, V. A. \& Brooks, H. E. Climate and hazardous convective weather. Curr. Clim. Change Rep. 1, 60-73 (2015).

41. Brooks, H. E. Severe thunderstorms and climate change. Atmos. Res. 123, 129-138 (2013).

42. Lanicci, J. M. \& Warner, T. T. A synoptic climatology of the elevated mixed-layer inversion over the southern Great Plains in spring. Part I: Structure, dynamics, and seasonal evolution. Wea. Forecast. 6, 181-197 (1991)

43. Gonzalez, P. et al. Southwest. in Impacts, Risks, and Adaptation in the United States: Fourth National Climate Assessment, Volume II (eds. Reidmiller, D. R. et al.) 1101-118. https://doi.org/10.7930/NCA4.2018.CH25 (U.S. Global Change Research Program, 2018)

44. Banacos, P. C. \& Ekster, M. L. The association of the elevated mixed layer with significant severe weather events in the northeastern United States. Wea. Forecast. 25, 1082-1102 (2010).

45. Trapp, R. J. et al. Changes in severe thunderstorm environment frequency during the 21 st century caused by anthropogenically enhanced global radiative forcing Proc. Natl Acad. Sci. 104, 19719-19723 (2007).

46. Diffenbaugh, N. S., Scherer, M. \& Trapp, R. J. Robust increases in severe thun derstorm environments in response to greenhouse forcing. Proc. Natl Acad. Sci. USA 110, 16361-16366 (2013).

47. Gensini, V. A., Ramseyer, C. \& Mote, T. L. Future convective environments using NARCCAP. Int. J. Climatol. 34, 1699-1705 (2014).

48. Gensini, V. A. \& Mote, T. L. Downscaled estimates of late 21 st century severe weather from CCSM3. Climatic Change 129, 307-321 (2015).

49. Seeley, J. T. \& Romps, D. M. The effect of global warming on severe thunderstorms in the United States. J. Clim. 28, 2443-2458 (2015).

50. Hoogewind, K. A., Baldwin, M. E. \& Trapp, R. J. The impact of climate change on hazardous convective weather in the United States: Insight from high-resolution dynamical downscaling. J. Clim. 30, 10081-10100 (2017)

51. Mahoney, K., Alexander, M. A., Thompson, G., Barsugli, J. J. \& Scott, J. D. Changes in hail and flood risk in high-resolution simulations over Colorado's mountains. Nat. Clim. Change 2, 125-131 (2012).

52. Brimelow, J. C., Burrows, W. R. \& Hanesiak, J. M. The changing hail threat over North America in response to anthropogenic climate change. Nat. Clim. Change 7, 516-522 (2017).
53. King, A. T. \& Kennedy, A. D. North American supercell environments in atmospheric reanalyses and RUC-2. J. Appl. Meteor. Climatol. 58, 71-92 (2019).

54. Czernecki, B. et al. Application of machine learning to large hail prediction-the importance of radar reflectivity, lightning occurrence and convective parameters derived from ERA5. Atmos. Res. 227, 249-262 (2019).

55. Blumberg, W. G. et al. SHARPpy: an open-source sounding analysis toolkit for the atmospheric sciences. Bull. Am. Meteor. Soc. 98, 1625-1636 (2017).

56. Sen, P. K. Estimates of the regression coefficient based on Kendall's tau. J. Am. Stat. Assoc. 63, 1379-1389 (1968).

57. Gelaro, R. et al. The modern-era retrospective analysis for research and applications, version 2 (MERRA-2). J. Clim. 30, 5419-5454 (2017).

58. Murillo, E. M. \& Homeyer, C. R. Severe hail fall and hail storm detection using remote sensing observations. J. Appl. Meteor. Climatol. 58, 947-970 (2019).

\section{ACKNOWLEDGEMENTS}

Brian Tang was supported through a grant from the Risk Prediction Initiative of the Bermuda Institute of Ocean Sciences.

\section{AUTHOR CONTRIBUTIONS}

Brian Tang led the analysis of LHP/SHIP days and its statistical relationship to LHR days and MESH days. Vittorio Gensini contributed data and to the analysis of LHR days. Cameron Homeyer contributed data and to the analysis of MESH days. Substantial collaboration between the authors occurred to interpret the results and write this paper.

\section{COMPETING INTERESTS}

The authors declare no competing interests.

\section{ADDITIONAL INFORMATION}

Supplementary information is available for this paper at https://doi.org/10.1038/ s41612-019-0103-7.

Correspondence and requests for materials should be addressed to B.H.T.

Reprints and permission information is available at http://www.nature.com/ reprints

Publisher's note Springer Nature remains neutral with regard to jurisdictional claims in published maps and institutional affiliations.

Open Access This article is licensed under a Creative Commons Attribution 4.0 International License, which permits use, sharing, adaptation, distribution and reproduction in any medium or format, as long as you give appropriate credit to the original author(s) and the source, provide a link to the Creative Commons license, and indicate if changes were made. The images or other third party material in this article are included in the article's Creative Commons license, unless indicated otherwise in a credit line to the material. If material is not included in the article's Creative Commons license and your intended use is not permitted by statutory regulation or exceeds the permitted use, you will need to obtain permission directly from the copyright holder. To view a copy of this license, visit http://creativecommons. org/licenses/by/4.0/.

(c) The Author(s) 2019 